\title{
Efficacy of Cooling Beef Taco Meat and Steamed Rice in United States School Foodservice Operations
}

\author{
David A. Olds ${ }^{1 \#}$, Kevin R. Roberts ${ }^{2}$, Kevin L. Sauer², Jeannie Sneed ${ }^{2}$, Carol W. Shanklin ${ }^{3}$ \\ ${ }^{1}$ Department of Family and Consumer Sciences, Bradley University, Peoria, USA; ${ }^{2}$ The Center of Excellence for Food Safety Re- \\ search in Child Nutrition Programs, Department of Hospitality Management and Dietetics, Kansas State University, Manhattan, USA; \\ ${ }^{3}$ Graduate School \& the Center of Excellence for Food Safety Research in Child Nutrition Programs, Department of Hospitality \\ Management and Dietetics, Kansas State University, Manhattan, USA. \\ Email: \#dolds@fsmail.bradley.edu
}

Received May $9^{\text {th }}, 2013$; revised June $9^{\text {th }}, 2013$; accepted June $16^{\text {th }}, 2013$

Copyright (c) 2013 David A. Olds et al. This is an open access article distributed under the Creative Commons Attribution License, which permits unrestricted use, distribution, and reproduction in any medium, provided the original work is properly cited.

\begin{abstract}
Food is frequently cooked, cooled and reheated for service at a later time in schools and other foodservice operations in the United States [US]. Inadequate cooling of food has been associated with foodborne illness. The purpose of this study was to determine if practices commonly used in school foodservice to cool beef taco meat and steamed rice would meet US Food and Drug Administration [FDA] 2009 Food Code standards. Prepared products cooled at $5.08 \mathrm{~cm}$ and $7.62 \mathrm{~cm}$ depths in stainless steel counter pans were placed uncovered in a walk-in refrigerator, a walk-in freezer (beef taco meat only), and a walk-in refrigerator with an ice water bath. Data were analyzed using descriptive statistics, including mean times and temperatures, with standard deviations. Cooling beef taco meat in a walk-in freezer at a depth of two inches and cooling steamed rice in a walk-in refrigerator at a depth of two inches with an ice water bath were the only methods that met both FDA Food Code time and temperature standards. Results suggest that challenges and risks exist with common methods used to cool food, especially if food volume is not reduced before cooling. Specific protocols for cooling procedures based on types of food and equipment are needed. These findings and recommendations are important for foodservice professionals who oversee food services and cooling practices in schools and other operations.
\end{abstract}

Keywords: Cooling; Schools; Foodservice; FDA; Food Code

\section{Introduction}

Approximately 12.1 million children are served breakfast in schools each day [1] and over 31 million children are served daily in the United States [US] National School Lunch Program [2]. Due to the large numbers of children served, food safety is paramount. To improve food safety, the Child Nutrition and WIC [Women, Infants, and Children] Reauthorization Act of 2004 required all schools to have a food safety program based on Hazard Analysis Critical Control Point [HACCP] principles [3].

When planning food safety programs, school foodservice directors identified cooling as a potential critical control point that needed attention. Between 1961 and 1982, inadequate cooling of food was the leading contributing factor in 1918 cases of C. perfringens foodborne illness outbreaks in the US [4]. The Centers for

\footnotetext{
*Authors declare no conflict of interest.

\#Corresponding author.
}

Disease Control and Prevention [CDC] estimated that $C$. perfringens bacteria, a bacteria often associated with improper food temperatures, accounted for $10 \%$ of the 9.4 million cases of foodborne illness that occur annually in the US [5]. The US General Accounting Office [6] reported 447,483 cases of foodborne illness and 15,831 foodborne outbreaks between 1973 and 1999, resulting in 20,119 hospitalizations and 457 fatalities. From 1973 to 1997, 604 foodborne disease outbreaks were reported in US schools, a median of 25 per year [7]. From 1990 to 1999, improper cooling was identified in five of 19 outbreaks in school foodservice operations [6]. Inadequate or "slow" cooling of food prepared on school premises was ranked third in the top 10 reportedcontributingfactorsin16of 298 school-associated foodborne outbreaks from 1998-2006 [8].

Krishnamurthy and Sneed [9] reported that $78 \%$ of surveyed school foodservice directors cooled leftovers to 
reheat and serve at another meal. Foods often cooled in more than half of all schools included taco meat, turkey (whole or roasts), and chili. Cooling most often was done in walk-in refrigerators or walk-in freezers, and few facilities (8\%) had blast chillers to speed the cooling process. The majority of schools did not monitor product temperatures during the cooling process. These findings in schools are consistent with a recent study that found that many restaurants do not verify cooling, do not monitor time and temperature during cooling, and do not calibrate thermometers [10].

Cooling standards in the 2009 US Food and Drug Administration [FDA] Food Code specify that cooked potentially hazardous food shall be cooled within two hours from $57.2^{\circ} \mathrm{C}$ to $21.1^{\circ} \mathrm{C}$ and within a total of six hours from $57.2^{\circ} \mathrm{C}$ to $5^{\circ} \mathrm{C}$ or less [11]. The FDA considers cooling to be a critical control point, "a point or procedure in a specific food system where loss of control may result in an unacceptable health risk" [11]. The 2009 FDA Food Code outlines acceptable cooling methods based upon the type of food product to be cooled. These cooling methods include placing food in shallow pans, portioning food into thinner or smaller amounts, employing the use of specialized equipment to cool food rapidly, stirring food in a container placed in an ice water bath, utilizing containers that allow heat transfer, adding ice to the food product, or other methods that facilitate the cooling process [11]. The 2009 FDA Food Code identifies methods used to meet cooling standards, but it does not specify procedures for monitoring cooling or provide guidelines for foodservice operators or inspectors to verify if cooling standards are being met. Snyder and Labalestra [12] stated that health departments have not conducted cooling studies to verify the FDA cooling standard in retail foodservice.

Previous research has established that challenges exist to achieving FDA Food Code standards for cooling bulk foods [12-15]. Research by Roberts et al. [13] examined the efficacy of various cooling methods for liquid foods. When comparing $5.08 \mathrm{~cm}$ and $7.62 \mathrm{~cm}$ depths of chili and tomato sauce cooled in a walk-in refrigerator and freezer, only products cooled at a $5.08 \mathrm{~cm}$ depth in a freezer met FDA Food Code standards. The use of an ice water bath decreased the initial cooling time of products in a refrigerator, but the ice water bath was not changed during the cooling process because typical school cooling processes were being replicated. Although rapid cooling of food is a known preventative measure to outbreaks of foodborne illness, limited information exists about which cooling methods meet FDA Food Code standards in foodservice operations.

The purpose of this study was to determine if cooling practices commonly used in school foodservice operations in the US to cool beef taco meat and rice would meet FDA Food Code standards. Cooling practices examined included $5.08 \mathrm{~cm}$ and $7.62 \mathrm{~cm}$ depths of products cooled in a walk-in refrigerator, walk-in freezer, and an ice water bath combined with the walk-in refrigerator.

\section{Methodology}

\subsection{Sample}

United States Department of Agriculture [USDA] recipes for schools, available online on the National Foodservice Management Institute's website [16], were used to prepare two products: "Beef or Pork Taco", USDA Recipe D-13 (hereafter referred to as beef taco meat); and "Cooking Rice”, USDA Recipe B-03 (hereafter referred to as steamed rice). Beef taco meat and steamed rice represent two food items that are prepared and cooled in the National School Lunch Program [9]. Beef taco meat was prepared in a standard steam-jacketed kettle and steamed rice was prepared in a standard convection steamer. Both pieces of equipment are often used in school foodservice.

\subsection{Cooling Procedures}

Three replications were conducted for each cooling method tested and three identically prepared and portioned food product samples were used in each replication. The mean cooling curves for each method and product tested were determined. Prior studies demonstrated that covered food products cooled slower than uncovered products $[14,17]$. Based on these findings, all food products tested were left uncovered during cooling.

Table 1 outlines the cooling methods. Cooling times and temperatures were logged at one minute intervals during testing using Comark RF512 wireless temperature transmitters (Comark Instruments, Beaverton, Oregon, USA) in conjunction with a Comark RF500A wireless monitoring gateway. A Comark RFAX100D thermistor was fixed in the geometric center of food products tested in $15.08 \mathrm{~cm} \times 50.8 \mathrm{~cm}$ stainless steel pans. Probes were fixed at $2.54 \mathrm{~cm}$ depths for food products tested at 5.08 $\mathrm{cm}$ product depths and at $3.81 \mathrm{~cm}$ depths for food products tested at $7.62 \mathrm{~cm}$ depths.

Prior to each replication, food products were prepared and portioned identically. An insert pan containing an ice water bath was used for replicates using the ice water bath method. For ice water bath replicates, pans of food product were lowered into insert pans $(15.08 \mathrm{~cm} \times 50.8$ $\mathrm{cm} \times 10.16 \mathrm{~cm}$ insert pans and $15.08 \mathrm{~cm} \times 50.8 \mathrm{~cm} \times$ $15.24 \mathrm{~cm}$ insert pans for $5.08 \mathrm{~cm}$ and $7.62 \mathrm{~cm}$ cooling methods, respectively) containing ice water (2:1 cubed ice to cold tap water ratio), which contacted the bottom and sides of the hot pans completely. Immediately following ice water bath insertion, replicates were placed in a walk-in refrigerator for the remainder of the cooling 
Table 1. Mean cooling times for beef taco meat and steamed rice using differing product depths and cooling methods.

\begin{tabular}{|c|c|c|c|c|}
\hline \multirow{2}{*}{ Food Product } & \multirow{2}{*}{ Product Depth } & \multirow{2}{*}{ Cooling Method } & \multicolumn{2}{|c|}{ Mean Cooling Time (hr:min) $\pm \mathrm{SD}^{1}$} \\
\hline & & & $57.2^{\circ} \mathrm{C}-21.1^{\circ} \mathrm{C}$ & $57.2^{\circ} \mathrm{C}-5^{\circ} \mathrm{C}$ \\
\hline Beef Taco Meat & $5.08 \mathrm{~cm}$ & Walk-in freezer & $1: 47 \pm 0: 14$ & $3: 19 \pm 0: 24$ \\
\hline Beef Taco Meat & $5.08 \mathrm{~cm}$ & Ice water bath in walk-in refrigerator & $1: 05 \pm 0: 06$ & $7: 30 \pm 1: 34$ \\
\hline Beef Taco Meat & $5.08 \mathrm{~cm}$ & Walk-in refrigerator & $3: 01 \pm 0: 18$ & $9: 19 \pm 1: 01$ \\
\hline Beef Taco Meat & $7.62 \mathrm{~cm}$ & Walk-in freezer & $3: 04 \pm 0: 19$ & $5: 22 \pm 0: 31$ \\
\hline Beef Taco Meat & $7.62 \mathrm{~cm}$ & Ice water bath in walk-in refrigerator & $3: 00 \pm 0: 17$ & $15: 48 \pm 1: 08$ \\
\hline Beef Taco Meat & $7.62 \mathrm{~cm}$ & Walk-in refrigerator & $4: 55 \pm 0: 14$ & $15: 24 \pm 0: 34$ \\
\hline Steamed Rice ${ }^{2}$ & $5.08 \mathrm{~cm}$ & Ice water bath in walk-in refrigerator & $1: 04 \pm 0: 05$ & $3: 04 \pm 0: 13$ \\
\hline Steamed Rice & $5.08 \mathrm{~cm}$ & Walk-in refrigerator & $3: 18 \pm 0: 17$ & $9: 55 \pm 0: 53$ \\
\hline Steamed Rice & $7.62 \mathrm{~cm}$ & Ice water bath in walk-in refrigerator & $2: 02 \pm 0: 11$ & $7: 11 \pm 1: 15$ \\
\hline Steamed Rice & $7.62 \mathrm{~cm}$ & Walk-in refrigerator & $4: 32 \pm 0: 18$ & $13: 37 \pm 0: 40$ \\
\hline \multicolumn{3}{|c|}{ FDA 2009 FOOD CODE COOLING STANDARDS ${ }^{3}$} & 2:00 & 6:00 \\
\hline
\end{tabular}

${ }^{1}$ Standard deviation; ${ }^{2}$ Steamed rice was not tested in a walk-in freezer because this method is not commonly used in United States [US] school foodservice operations; ${ }^{3}$ US Food and Drug Administration [FDA].

process. The ice water bath was not replaced during the cooling process to simulate food handling procedures previously observed in foodservice operations [18]. For each replication, a maximum of four pans was placed in the walk-in refrigerator or walk-in freezer during testing. Following placement of food products into the walk-in refrigerator/freezer, doors were securely locked and remained closed until the cooling process had concluded.

\section{Results and Discussion}

Average cooling curves for beef taco meat and steamed rice cooling methods are shown in Figures $\mathbf{1}$ and 2, respectively. The only cooling method for the beef taco meat that met both FDA standards (food product cooled from $57.2^{\circ} \mathrm{C}$ to $21.1^{\circ} \mathrm{C}$ within two hours and $57.2^{\circ} \mathrm{C}$ to $5^{\circ} \mathrm{C}$ within a total of six hours) was when the product was at a $5.08 \mathrm{~cm}$ depth and cooled in a walk-in freezer. The only steamed rice method that met both FDA standards was when the product was cooled in an ice water bath placed in a walk-in refrigerator at a $5.08 \mathrm{~cm}$ product depth. Interestingly, the steamed rice cooled at a $5.08 \mathrm{~cm}$ depth in an ice water bath met FDA standards while beef taco meat cooled using the same method did not, illustrating that the physical nature of the product being cooled impacts the cooling process. Steamed rice was not tested in a walk-in freezer because this cooling method is not commonly used in foodservice operations. It is recommended that steamed rice be cooled rapidly at a 5.08 $\mathrm{cm}$ depth or less using an ice water bath in a walk-in refrigerator to ensure that FDA standards are met.

Beef taco meat cooled using an ice water bath in the walk-in refrigerator at a $5.08 \mathrm{~cm}$ depth met the first FDA 2009 Food Code standard $\left(57.2^{\circ} \mathrm{C}\right.$ to $21.1^{\circ} \mathrm{C}$ within two hours), but failed to cool from $57.2^{\circ} \mathrm{C}$ to $5^{\circ} \mathrm{C}$ within a total of six hours. Beef taco meat cooled in the walk-in freezer at a $7.62 \mathrm{~cm}$ depth failed to meet the first FDA standard of $57.2^{\circ} \mathrm{C}$ to $21.1^{\circ} \mathrm{C}$ within two hours, but did cool from $57.2^{\circ} \mathrm{C}$ to $5^{\circ} \mathrm{C}$ within the required six hours. Neither food product cooled within the recommended FDA standards using the walk-in refrigerator or the ice water bath in the walk-in refrigerator at $7.62 \mathrm{~cm}$ depths.

For all cooling methods, each food product required a longer cooling time at $7.62 \mathrm{~cm}$ depths than at $5.08 \mathrm{~cm}$ depths. None of the $7.62 \mathrm{~cm}$ cooling methods tested on either food product met both FDA 2009 Food Code time and temperature cooling standards. The method taking the longest time to cool was the beef taco meat in an ice water bath in a walk-in refrigerator at a $7.62 \mathrm{~cm}$ depth. This product required longer than the same $7.62 \mathrm{~cm}$ depth of beef taco meat in a walk-in refrigerator without the ice water bath. The use of an ice water bath did increase the cooling rate of beef taco meat from $57.2^{\circ} \mathrm{C}$ to $21.1^{\circ} \mathrm{C}$, however, once the ice had melted, the additional volume of warmed water inhibited rapid cooling compared to the same product tested in the walk-in refrigerator without an ice water bath at the same $7.62 \mathrm{~cm}$ depth. Ice water baths speed the cooling process, but if they are not changed once the ice has melted, it can actually increase the overall cooling time. This study was designed to simulate practices in schools, where employees leave work after food production has concluded, thus being unable to actively cool or monitor food products. Therefore, ice water bath insert pans were not changed and remained in place throughout all ice water bath replications.

\section{Conclusions}

Results show that cooling food properly is difficult and may pose a food safety risk, especially if the volume of food is not greatly reduced before cooling. Previous 


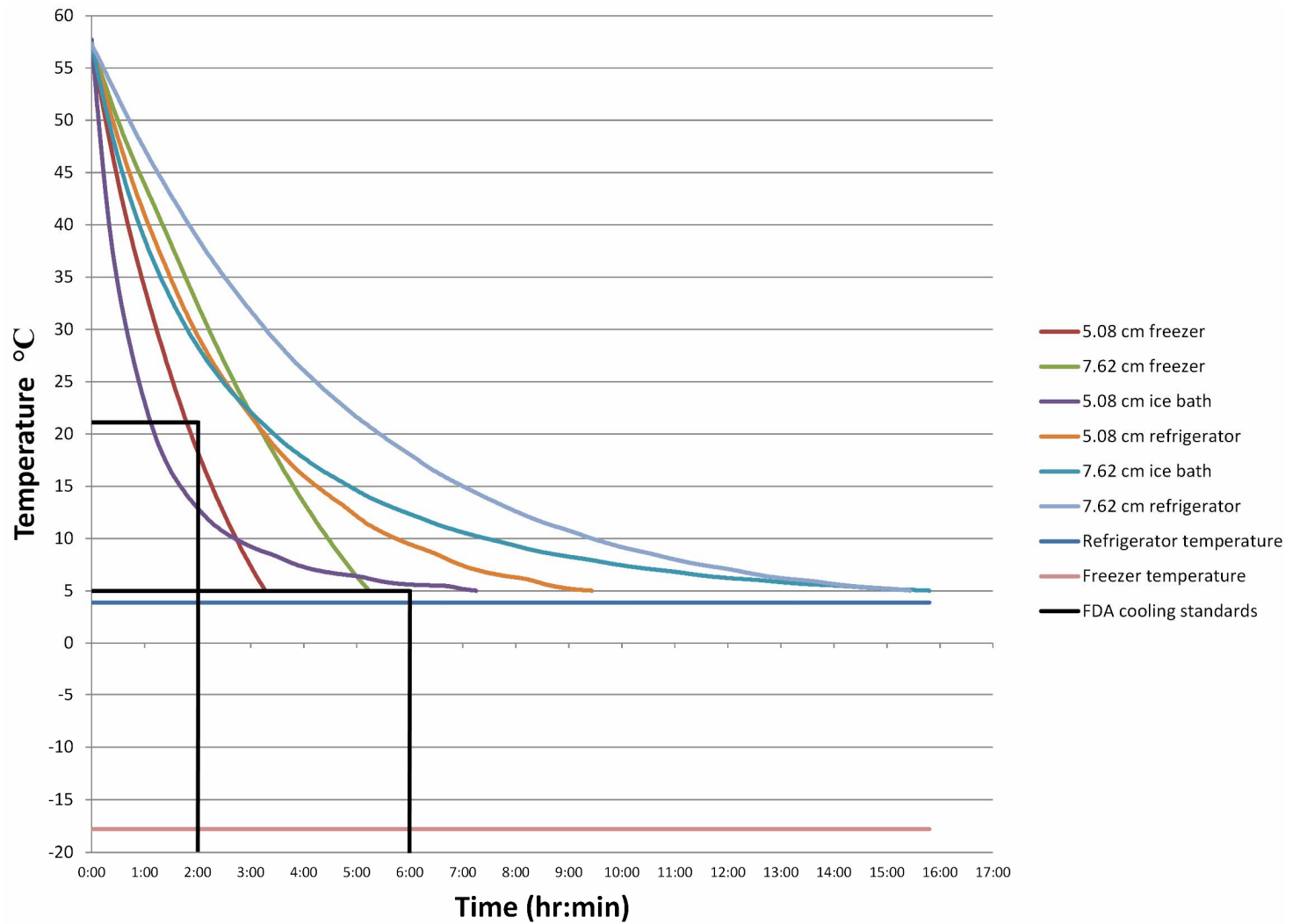

Figure 1. Cooling curves for cooling beef taco meat.
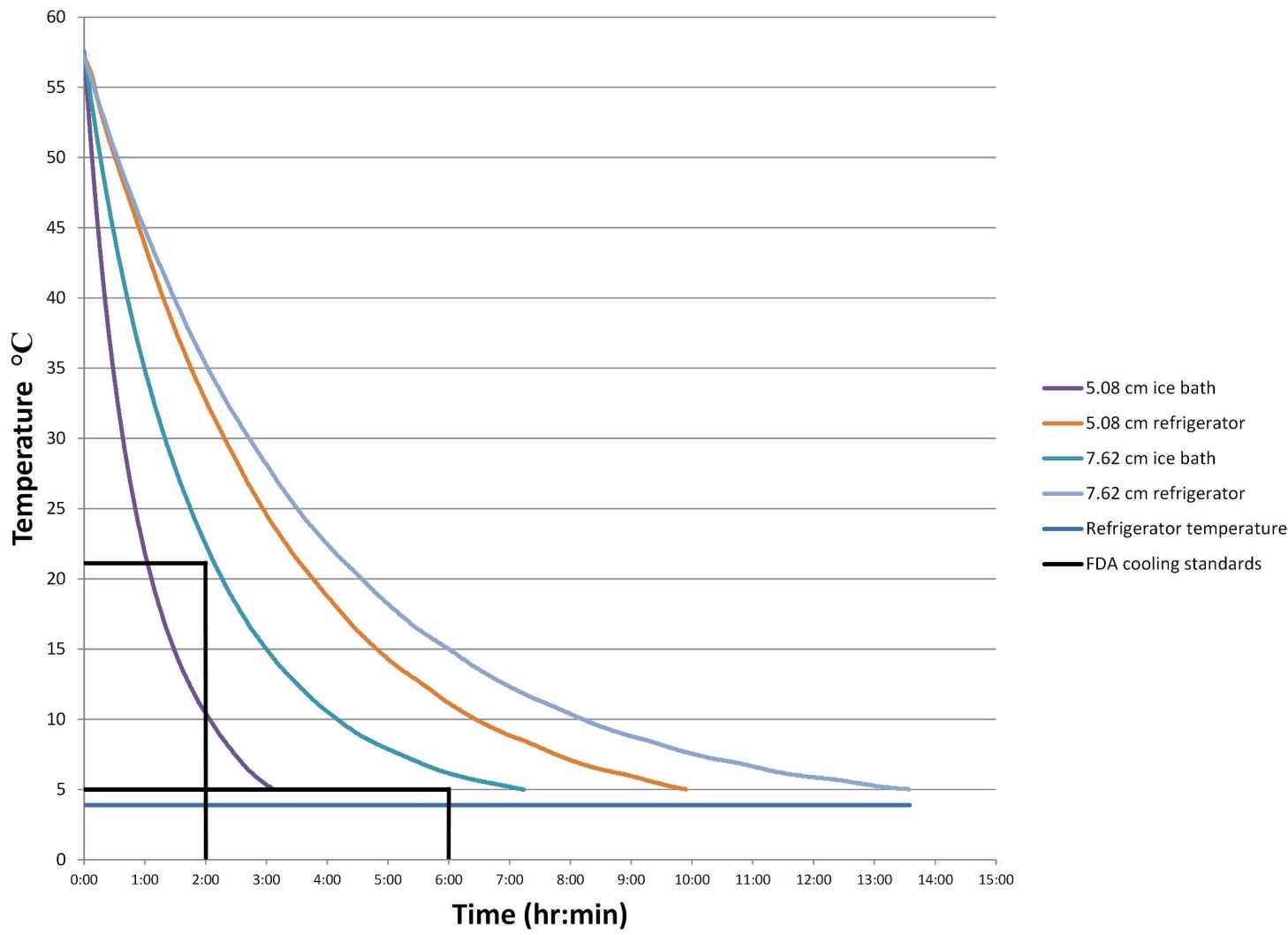

Figure 2. Cooling curves for cooling steamed rice. 
research demonstrated that blast chillers, which use forced air, can effectively cool foods to FDA 2009 Food Code standards [15]. However, blast chillers are expensive and the financial resources may not be available in many school foodservice operations to purchase them even though the need for rapid cooling equipment exists. This is supported by findings of Krishnamurthy and Sneed [9] who surveyed 411 school foodservice directors/managers and found that only $8 \%$ of those operations had blast chillers available.

Foodservice operations require economical methods to safely cool a wide variety of foods. Managers faced with limited financial resources rely on refrigerators, freezers, or ice water baths as practical means to safely cool food products of $5.08 \mathrm{~cm}$ depths or less. However, freezers may not be suitable if there is insufficient time to reheat frozen food in time for service following cooling. As shown in this study, ice water baths are suitable for porous foods, such as rice, but are not suitable for denser foods that do not permit cool air to penetrate the food product and promote heat transfer. School foodservice personnel may not distinguish between products that should be cooled with ice water baths versus other methods. Cooling foods in freezers may pose a challenge if adequate space does not exist to accommodate cooling along with regular and safe storage of frozen food products.

Specific recommendations for cooling procedures based on specific types of food and equipment should be developed and shared with foodservice managers in all types of foodservice operations. These managers need to monitor cooling times and temperatures to ensure that cooling practices are effective for their operation based on food, equipment, load of the cooling unit, and other factors that influence cooling.

Future research should further explore the recommended cooling methods in the FDA 2009 Food Code. Specific instructions, based on sound science and research, should be provided to foodservice operators who wish to cool large amounts of food product. For example, the current code recommends cooling food in an ice water bath while stirring. However, specific information about how often the product should be stirred and the maximum depth needed to cool the food properly should also be provided.

FDA Food Code standards for time and temperature could be validated for microbiological growth of pathogens in environments that more closely simulate food production in school foodservice operations. This study found that barriers exist to proper food cooling even under best-case scenarios. Further research is suggested to determine which cooling methods could be effectively implemented in foodservice operations, while also meeting FDA 2009 Food Code standards to cool cooked po- tentially hazardous food. Recommended cooling procedures should be added to the USDA standardized recipes and to policy and procedures manuals within each school and/or district.

Results of this study can be applied to any foodservice operation. Food service professionals in restaurants, medical centers, long-term care and assisted living facilities, and college and universities can implement recommendations to improve cooling in those operations.

\section{Acknowledgements}

This research project was conducted at Kansas State University and was federally funded, in part, by the US Department of Agriculture [USDA]. This research does not necessarily reflect the views or policies of the USDA, nor do mentions of organizations, commercial products, or trade names within this publication suggest or imply endorsement by the United States Government.

\section{REFERENCES}

[1] United States Department of Agriculture Food and Nutrition Service, “The School Breakfast Program,” 2013. http://www.fns.usda.gov/cnd/breakfast/AboutBFast/SBPF actSheet.pdf

[2] United States Department of Agriculture Food and Nutrition Service, “National School Lunch Program,” 2013. http://www.fns.usda.gov/cnd/lunch/aboutlunch/NSLPFact Sheet.pdf

[3] United States Department of Agriculture Food and Nutrition Service, "The Child Nutrition and WIC Reauthorization Act of 2004. Public Law 108-265, Section 111,” 2004.

http://www.fns.usda.gov/cnd/governance/legislation/histo rical/pl_108-265.pdf

[4] F. L. Bryan, "Risks of Practices, Procedures, and Processes that Lead to Outbreaks of Foodborne Diseases," Journal of Food Protection, Vol. 51, No. 8, 1988, pp. 663-673.

[5] E. Scallan, R. M. Hoekstra, F. J. Angulo, R. V. Tauxe, M. A. Widdowson, S. L. Roy, J. L. Jones and P. M. Griffin, "Foodborne Illness Acquired in the United States-Major Pathogens," Emerging Infectious Diseases, Vol. 17, No. 1, 2011, pp. 7-15. doi:10.3201/eid1701.09-1101p1

[6] US General Accounting Office, “GAO: School Meal Programs: Few Outbreaks of Foodborne Illness Reported, but Opportunities Exist to Enhance Outbreak Data and Food Safety Practices,” 2003.

http://www.gao.gov/products/GAO-03-530

[7] N. A. Daniels, L. Mackinnon, S. M. Rowe, N. H. Bean, P. M. Griffin and P. S. Mead, "Foodborne Disease Outbreaks in United States Schools," Pediatric Infectious Disease Journal, Vol. 21, No. 7, 2002, pp. 623-628. doi:10.1097/00006454-200207000-00004

[8] L. T. Pogostin, S. Ayers, T. Gray, M. Nguyen, M. Lynch and I. Williams, "School-Associated Foodborne Outbreaks 
in the United States-1998-2006," The 4th Annual Outbreak Net Conference, Denver, 6 June 2008.

[9] K. Krishnamurthy and J. Sneed, "Cooling Practices Used in School Foodservice,” Food Protection Trends, Vol. 31, No. 12, 2011, pp. 828-833.

[10] L. G. Brown, D. Ripley, H. Blade, D. Reiman, K. Everstine, D. Nicholas, J. Egan, N. Koktavy and D. N. Quilliam, "Restaurant Food Cooling Practices," Journal of Food Protection, Vol. 75, No. 12, 2012, pp. 2172-2178. doi:10.4315/0362-028X.JFP-12-256

[11] US Food and Drug Administration, "FDA: Food Code 2009,” 2009. http://www.fda.gov/Food/FoodSafety/RetailFoodProtecti on/FoodCode/FoodCode2009/

[12] O. P. Snyder and J. A. Labalestra, "Comparison of the Bimetallic Coil Thermometer and Thermocouple for Validating Food Cooling," Food Protection Trends, Vol. 24, No. 6, 2004, pp. 423-428.

[13] K. R. Roberts, D. A. Olds, C. Shanklin, K. Sauer and J. Sneed, "Cooling of Foods in Retail Foodservice Operations,” Food Protection Trends, Vol. 33, No. 1, 2013, pp. 27-31.

[14] D. A. Olds, A. F. Mendonca, J. Sneed and B. Bisha, “In- fluence of Four Retail Foodservice Cooling Methods on the Behavior of Clostridium perfringens ATCC 10388 in Turkey Roasts Following Heating to an Internal Temperature of $74^{\circ} \mathrm{C}$," Journal of Food Protection, Vol. 69, No. 1, 2006, pp. 112-117.

[15] D. A. Olds and J. Sneed, "Cooling Rates of Chili Using Refrigerator, Blast Chiller, and Chill Stick Cooling Methods,” Journal of Child Nutrition \& Management, Vol. 29, No. 1, 2005.

http://docs.schoolnutrition.org/newsroom/jcnm/05spring/

[16] National Foodservice Management Institute, "NFSMI: USDA Recipes for Schools,” 2013. http://www.nfsmi.org/Templates/TemplateDefault.aspx?q

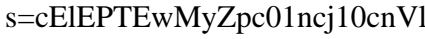

[17] Institute for Food Safety and Health, "USDA-FNS/FDA/ IFSH Study on Cooling of Foods in School Food Service Operations, Final Report,” 2011.

[18] D. Henroid and J. Sneed, "Readiness to Implement Hazard Analysis and Critical Control Point (HACCP) Systems in Iowa Schools," Journal of the American Dietetic Association, Vol. 104, No. 6, 2004, pp. 180-185. doi:10.1016/j.jada.2003.11.009 